\title{
Prostaglandin-targeting agents and spectral heart rate variability in experimental partial bladder outlet obstruction in rats
}

\author{
Ł Dobrek, A Baranowska, B Skowron, A Furgała, D Żurowski, P Thor \\ Department of Pathophysiology, Faculty of Medicine, Jagiellonian University Medical College, \\ Cracow, Poland
}

Received: May 19, 2014

Accepted: December 1, 2014

\begin{abstract}
The purpose of this study was to determine the activity of the autonomic nervous system (ANS), using spectral analysis of the heart rate variability (HRV) in the model of partial bladder outlet obstruction (PBOO) in rats treated with selected non-steroidal anti-inflammatory drugs (NSAID): piroxicam (PRX) or meloxicam (MLX), and following administration of PGF2 $\alpha$ prostaglandin analogue (Enzaprost F5). Neither the use of PGF2 $\alpha$ analogue nor of MLX, caused significant changes in the HRV spectrum (except for HRV spectrum total power reduction with MLX). The use of PRX caused reduction of the total power and powers of all components of the HRV spectrum (except for VLF). Moreover, increased nLF and reduced nHF were observed. The obtained results suggest that the total prostaglandin synthesis block with a non-selective cyclooxygenase inhibitor (PRX) results in reduced ANS total activity, with decreased parasympathetic activity and a relative sympathetic predominance. The preferential cyclooxygenase-2 block (MLX) caused reduction of the total ANS activity as well, however with no clear disproportion of any part of the ANS. Therefore, prostaglandin synthesis inhibition and associated decrease of parasympathetic activity may constitute an additional and favourable feature of NSAID pharmacodynamics in the treatment of BPH.
\end{abstract}

Keywords: heart rate variability, autonomic nervous system, bladder, piroxicam, meloxicam, prostaglandins

Bladder overactivity as a secondary condition (secondary overactive bladder; $\mathrm{OAB}$ ) develops in course of organic illnesses. One of them is benign prostatic hyperplasia (BPH). In course of that disease, bladder overactivity is a result of compression of hypertrophic prostatic tissue on proximal section of the urethra, resulting in compromised urine outflow and progressive pressure increase in lower urinary tract.

Pathophysiological description of BPH postulates the role of higher dihydrotestosterone and fibroblastic/vascular growth factors content in prostatic tissues as well as local prostatic hypoxia and inflammation that result in remodelling of prostatic tissues $(8,34)$. There are also reports regarding a close association between BPH development and co-existence of metabolic syndrome in the same patient. That would suggest the role of hyperinsulinaemia and insulin resistance combined with higher sympathetic activity and explained exacerbation of BPH in patients with coexistent diabetes (6).

The current, classic pharmacotherapy of BPH involves the use of $\alpha-1$ adrenolytics ( $\alpha-1$ adrenergic receptor antagonists) and 5- $\alpha$ reductase inhibitors as monotherapy or combined

Corresponding author: Dr Łukasz Dobrek MD, $\mathrm{PhD}$

Department of Pathophysiology, Faculty of Medicine, Jagiellonian University Medical College

ul. Czysta 18, 31-121 Krakow, Poland

Phone/Fax: +48-12-6329056; E-mail: lukaszd@mp.pl 
therapy $(23,28)$. There are also reports indicating a favourable effect of cholinolytic drugs and phosphodiesterase inhibitors - those two classes of compounds are being tested in several clinical trials assessing their efficacy and safety in BPH pharmacotherapy (28).

In face of a relatively few pharmacological options of BPH therapy, studies focused on development of new, potentially effective compounds are being performed. Potential new drugs are: $\beta 3$ adrenergic drugs ( $\beta 3$ adrenergic receptor agonists), $\mathrm{P} 2 \mathrm{X}$ purinergic receptor, endoteline receptors (ETA / ETB) or angiotensin receptors (AT1 / AT2) antagonists, vitamin D3 analogues and Rho kinase inhibitors $(2,41)$.

Among the currently studied drugs for BPH treatment there are also non-steroidal antiinflammatory drugs (NSAID), both non-selective and selective cyclooxygenase (COX) inhibitors. Araki et al. (3) demonstrated that administration of loxoprofen, as an addition to the standard $\alpha-1$ adrenolytic BPH therapy, reduced nocturnal miction episodes. Falahatkar et al. (14) demonstrated that the addition of $100 \mathrm{mg}$ celecoxib to the standard therapy with $\alpha-1$ adrenolytics and 5- $\alpha$ reductase inhibitors in patients with multiple nocturia episodes caused reduction of frequency of those episodes by half. Effectiveness and efficacy of NSAID supplementation of BPH pharmacotherapy were also demonstrated by St. Sauver et al. (38) who demonstrated that everyday use of NSAID (aspirin in $80 \%$ of subjects; ibuprofen, diclofenac or naproxen in remaining 20\%) was negatively correlated with BPH symptoms exacerbation. Moreover, Kahokehr et al. (19) performed a systematic review of clinical trials focusing on the evaluation of clinical usefulness of NSAID in BPH. They confirmed existence of numerous and positive study reports, but at the same time they stated that aspects associated with safety of long-term use of those drugs in the condition remained unknown (19).

Considering the incomplete description of NSAID pharmacodynamics in BPH it seems important to determine if those drugs exert their potentially beneficial effect on BPHassociated bladder overactivity symptoms also by modulation of activity of the autonomic nervous system (ANS).

As BPH may be relatively easily modelled in study animals by surgical formation of a partial bladder outlet obstruction (PBOO), experimental simulation studies are possible (32). Also, the functional status of the ANS may be indirectly evaluated based on the assessment of the heart rate variability (HRV), based on recording of a mean time between subsequent $\mathrm{N}-\mathrm{N}$ (normal-normal) intervals in ECG in the aspect of spectral (frequency) analysis (26).

Therefore, our purpose was to evaluate the functional status of ANS using the HRV methodology in course of PBOO in rats treated with non-selective (COX-1 and -2 blocking) or with preferential (COX-2 blocking) cyclooxygenase inhibitor, as well as with PGF2 $\alpha$ prostaglandin analogue.

\section{Materials and Methods}

Ethical aspects of the experiment

The medical experiment constituting the basis for this report was approved by the $1^{\text {st }}$ Local Bioethics Committee for Animal Experiments in Krakow (no. 124/2013).

\section{General plan of the experiment}

The study was carried out in four groups (10 participants each) of 8-week-old Wistar rats. Group 1 was the control group, and pharmacological agents were administered to animals in groups $2-4$. On the first day of the experiment all animals had the procedure of partial bladder 
outlet obstruction. The PBOO model was evoked according to a surgical technique described in detail in one of our previous work (12).

On day 3 after surgery, study agents were introduced (intraperitoneally; i.p.) to groups 2-4 and placebo was introduced in group 1. The administration was continued every other day. On day 14 after the PBOO surgery all animals had ECG recordings with subsequent analysis of heart rate variability. Moreover, after ECG registration, urodynamic studies were performed to assess bladder contractility due to infravesical partial obstruction in both control and treated rats. Standard urodynamic parameters were estimated. The detailed methodology of urodynamic recordings applied by us is given in our other paper (13). Then, following administration of a lethal dose of pentobarbital, cystectomy was performed in order to measure the bladder wet weight (BWW) and for subsequent histopathological evaluation. Initial (at the day of PBOO surgery) and final (on the day of ECG record) animal body weight was determined in all groups. Water and standard laboratory feed (Labofeed, Kcynia, Poland) consumption were not monitored throughout the experiment and animals had unlimited access to both water and feed.

\section{Studied pharmacological agents}

In all study groups, the pharmacological agents (groups 2-4) or normal saline (group 1) were administered intraperitoneally on the day 3, 5, 7, 9, 11 and 13 after the PBOO surgery. Group 2 received the PGF2 $\alpha$ prostaglandin analogue solution (commercially available product Enzaprost F5, ampoules $5 \mathrm{mg} / \mathrm{ml}$, Chinoin Pharmaceutical and Chemical Works Co. Ltd., Budapest, Hungary); groups 3 and 4 received cyclooxygenase inhibitors: meloxicam (MLX) or piroxicam (PRX), respectively. In those cases also commercially available products were used (meloxicam - Movalis, ampoules $15 \mathrm{mg} / 1.5 \mathrm{ml}$, Boehringer Ingelheim International $\mathrm{GmbH}$, Ingelheim am Rhein, Germany; piroxicam - Feldene, ampoules $20 \mathrm{mg} / \mathrm{ml}$, Pfizer Europe, Kent, UK). Rats in the group 1 - control - received injections of normal saline at the mean volume corresponding to the applied doses of Enzaprost/Feldene/Movalis. In the group 2 we used the PGF $2 \alpha$ prostaglandin analogue solution at the dose of $200 \mu \mathrm{g} / \mathrm{rat}$, corresponding to approx. $0.8-0.9 \mathrm{mg} / \mathrm{kg}$ b.w. Rats constituting group 3 were treated with MLX at the dose of $5 \mathrm{mg} / \mathrm{kg}$ b.w., while animals from group 4 received PRX at the dose of $10 \mathrm{mg} / \mathrm{kg} \mathrm{b}$.w.

Both in groups 1 and 2 one individual died during the early post-surgical period. Therefore, 9 animals were finally studied in both those groups. A higher mortality rate was observed in animals receiving MLX or PRX - 2 and 3 animals, respectively, had died before the final dosage of the study agent was administered.

\section{HRV records}

On day 15 of the experiment all animals were subjected to a short-term (20 minutes) ECG recording under general urethane anaesthesia (1200 mg/kg b.w., Sigma-Aldrich, Poznan, Poland) in accordance with the details described by us elsewhere (12). The choice of that anaesthetic agent was based on premises that compared to other pharmacological agents for general anaesthesia, that one had the less pronounced depressive effect on the ANS $(24,25)$. Directly before the ECG recording study animals received an additional intraperitoneal dose of the study agent (groups 2-4) or of normal saline (control).

After the registration the obtained ECG signal was evaluated visually in order to remove any ectopic beats, and the record was subjected to the spectral (frequency) HRV analysis using the Polygram set and software (ADInstruments Pty Ltd. Bella Vista, Australia; Chart v5.4.2 for Mac OS X Version 10.1.2). 
The spectral analysis involved evaluation of powers of components of the, so-called, HRV spectrum, that is distribution of changes of ECG normal-normal $(\mathrm{N}-\mathrm{N})$ beats intervals in relation to the cyclic, ANS-modulated stimulatory activity of the sinus node associated with three basic rhythms: very low (VLF), low (LF) and high (HF) frequency $(26,39)$. For the sake of this analysis we have adopted the following ranges for individual components of the HRV spectrum: $0.18<\mathrm{VLF}<0.28<\mathrm{LF}<0.78<\mathrm{HF}<3$. Those frequency ranges are similar to those adopted by Aubert et al. $(0.19<\mathrm{LF}<0.74<\mathrm{HF}<2.5)(5)$ and Goncalves et al. $(0.10<\mathrm{LF}<1.0<\mathrm{HF}<3.0)(15)$. The evaluation was completed in two ways - studying powers of individual, basic HRV components (VLF, LF, HF), and the total power (TP) of the spectrum expressed in power units $\left[\mathrm{ms}^{2}\right]$, as well as analysing percent changes of individual components (VLF [\%], LF [\%], HF [\%]) in relation to the total power of the spectrum, LF/ $\mathrm{HF}$ ratio and values of normalized $\mathrm{nLF}$ and $\mathrm{nHF}$ parameters expressed in [n.u.].

\section{Collection of bladders and their weight and histopathological assessment:}

Following the ECG and urodynamic recordings animals in all groups were sacrificed by intraperitoneal administration of a lethal anaesthetic dose of pentobarbital (Morbital, $100 \mathrm{mg}$ / kg b.w., Biowet Sp. z o.o., Poland) in order to collect urinary bladders for weighing and histopathological evaluation (using the hematoxylin-eosin staining). Bladders with the proximal, ligated section of the urethra were collected during a repeated laparotomy. Excised bladders were delicately dried on gauze compresses and opened carefully in order to empty them from retained urine, weighed on analytic scales and placed in $4 \%$ formalin solution. The measurement of bladder wet weight (BWW) is considered a general, non-specific marker of its pathological histological reconstruction $(35,42)$, occurring in $\mathrm{PBOO}$ as a result of pressure overload.

\section{Statistical analysis}

The statistical analysis was completed with the statistical suite R.3.0.2. (R Foundation for Statistical Computing, Vienna, Austria).

First, variance analysis (ANOVA) was used for verification of statistically significant differences between four study groups. Then, in case a statistical significance was demonstrated for a particular analysed parameter $(\mathrm{p}<0.05$ in ANOVA), differences between groups 1-2 (PBOO control vs. PBOO+PGF2 $\alpha$ ), 1-3 (PBOO control vs. PBOO+MLX) and 1-4 (PBOO control vs. PBOO + PRX) were analysed using the t-Student test. Both tests were made on logarithms of obtained HRV results. That procedure was applied to ensure higher concordance of those parameters with the normal distribution.

\section{Results}

The characteristics of study animals body weight and bladder wet weight

In the end of the experiment, reduced body weight was observed in all groups compared to baseline. The change was significant in group 4 (rats receiving PRX). A relatively worse condition of animals in that group could be associated with potential adverse effects of PRX on gastrointestinal (GI) tract mucosa.

The bladder wet weight was the highest in control rats and similar in group 3. Animals treated with PGF2 $\alpha$ analogue and PRX were characterized by lower BWW values and the differences compared to the control were significant. However, the value of the bladder wet 
weight ratio (BWW in relation to the final body weight) was tended to be lower in all treated groups with no statistical difference compared to the control. The characteristics of study animals and BWW results are presented in Table I.

Table I. Characteristics of studied groups

\begin{tabular}{|c|c|c|c|c|c|c|c|}
\hline & \multirow{2}{*}{$\begin{array}{c}\text { PBOO } \\
\text { Control } \\
\text { Group } 1\end{array}$} & \multirow{2}{*}{$\begin{array}{l}\text { PBOO + } \\
\text { PGF2 } \alpha \\
\text { Group } 2\end{array}$} & \multirow{2}{*}{$\begin{array}{l}\text { PBOO + } \\
\text { MLX } \\
\text { Group } 3\end{array}$} & \multirow{2}{*}{$\begin{array}{l}\text { PBOO + } \\
\text { PRX } \\
\text { Group } 4\end{array}$} & \multicolumn{3}{|c|}{ Statistic } \\
\hline & & & & & $\begin{array}{c}\text { Group } \\
1-2\end{array}$ & $\begin{array}{c}\text { Group } \\
1-3\end{array}$ & $\begin{array}{c}\text { Group } \\
1-4\end{array}$ \\
\hline $\begin{array}{l}\text { Starting body } \\
\text { weight }[\mathrm{g}]\end{array}$ & $230.7 \pm 9.9$ & $216.1 \pm 8.1$ & $230.6 \pm 15.02$ & $237.2 \pm 14.6$ & 0.01 & $\mathrm{NS}$ & $\mathrm{NS}$ \\
\hline $\begin{array}{l}\text { Final body weight } \\
{[\mathrm{g}]}\end{array}$ & $213.3 \pm 16.6$ & $203.8 \pm 14.9$ & $219.8 \pm 8.9$ & $178.2 \pm 10.7$ & NS & NS & 0.001 \\
\hline $\begin{array}{l}\text { Bladder wet weight } \\
(\mathrm{BWW})[\mathrm{mg}]\end{array}$ & $\begin{array}{c}438.6 \pm \\
291.0\end{array}$ & $\begin{array}{c}310.2 \pm \\
148.7\end{array}$ & $388.0 \pm 195.1$ & $\begin{array}{c}288.1 \pm \\
234.6\end{array}$ & 0.05 & NS & 0.05 \\
\hline $\begin{array}{l}\text { BWW }[\mathrm{g}] / \text { Final } \\
\text { body weight }[\mathrm{g}] \\
\text { ratio }\end{array}$ & $\begin{array}{c}0.0021 \pm \\
0.0020\end{array}$ & $\begin{array}{c}0.0015 \pm \\
0.0008\end{array}$ & $\begin{array}{c}0.0018 \pm \\
0.0010\end{array}$ & $\begin{array}{c}0.0016 \pm \\
0.0012\end{array}$ & NS & NS & NS \\
\hline
\end{tabular}

\section{Urodynamic recordings}

Comparing to findings revealed in normal rats in our another study (13), the PBOO rats (group 1) were characterised by an increase of peak number (both total amount and peaks per minute) along with intercontraction interval [s], threshold pressure $\left[\mathrm{cmH}_{2} \mathrm{O}\right]$ and micturition voiding pressure $\left[\mathrm{cmH}_{2} \mathrm{O}\right]$ decrease. These results confirmed bladder overactivity due to proximal urethral obstruction in PBOO control rats (group 1). The Enzaprost/Feldene/ Movalis treated animals (groups 2-4) demonstrated similar urodynamic features, with no signs of statistically significant improvement of bladder functioning, although in animals receiving PRX a trend of bladder overactivity reduction was observed. The urodynamic recording examples are given in Figs 1 and 2.

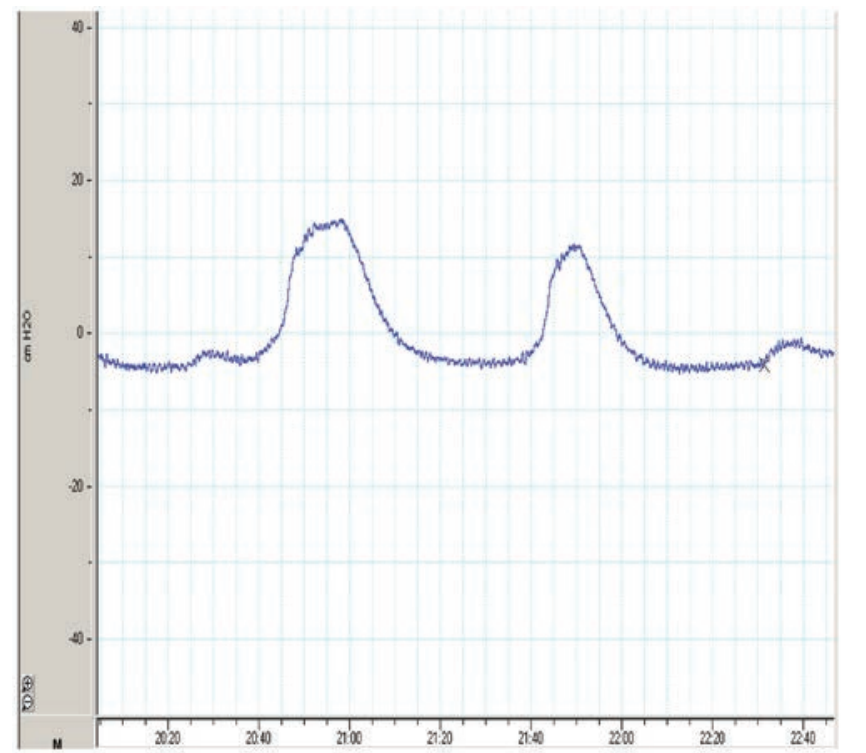

Fig. 1. The example of urodynamic recording obtained in normal rats in our another study (13) 


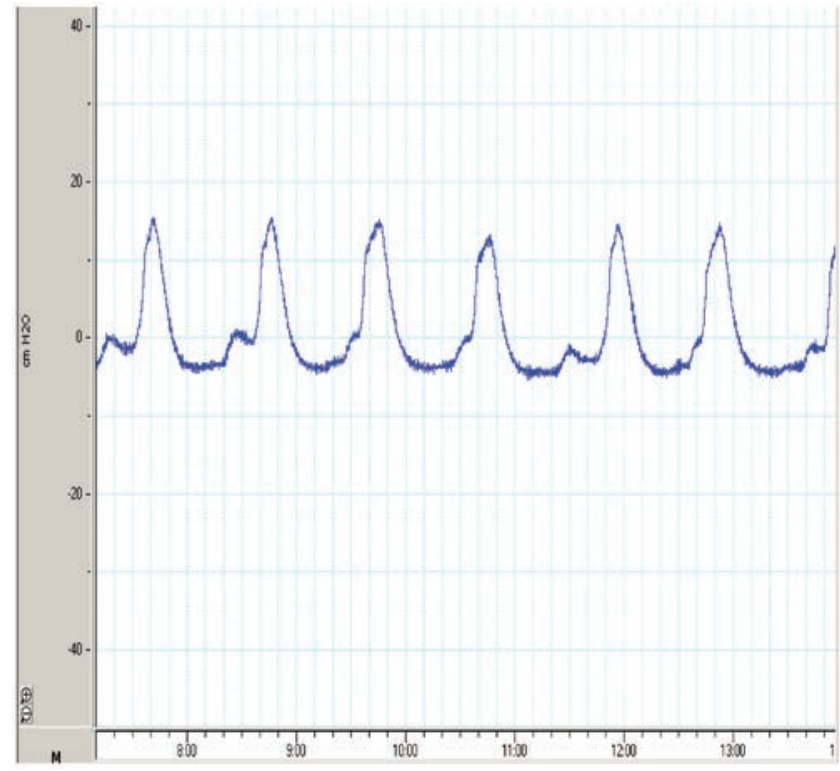

Fig. 2. The example of urodynamic recording obtained in partial bladder outlet obstruction (PBOO) control animals, confirming bladder overactivity

\section{Histopathological assessment of the collected bladders}

The histopathological evaluation of bladders collected from control animals (the PBOO group without any treatment) revealed signs of hyperaemia of the bladder wall and dilation of its lumen with signs of hyperaemia and oedema of the mucosal lamina propria. Moreover, some minor inflammatory infiltrations were revealed, made of small lymphocytes and single granulocytes, and a minimal hypertrophy of the bladder wall muscular coat.

In group 2 (PBOO + PGF2 $\alpha$ ) hyperaemia and dilation of the lumen were demonstrated, with signs of papillosis urothelialis fere completa; moreover, signs of a minor inflammation composed of small lymphocytes were revealed.

Bladders from PBOO animals treated with MLX (group 3) also demonstrated dilation of their lumen with signs of hyperaemia and marked intensification of oedema of the mucosa and of the whole bladder wall, with small extravasations and minor perivascular inflammatory infiltrations composed of small lymphocytes.

The histopathological presentation of rat bladders in group 4 (PBOO + PRX) corresponded to cystitis chronica partim ulcerosa et oedema et hyperaemia passiva parietis et pericystitis chronica.

Based on the obtained results of histopathological analysis it may be stated that rats with PBOO are characterised by histological reconstruction of the bladder. Those results confirm effectiveness of the applied surgical method and maintenance of the PBOO model throughout the whole experiment.

\section{HRV spectral (frequency) analysis}

Assessing powers of individual basic components of the HRV spectrum and its total power in group 2 (animals treated with PGF2 $\alpha$ analogue), no statistically significant differences compared to the control were demonstrated, except for the LF/HF ratio that reached lower values in group 2. Animals in group 3 (MLX-treated) were characterised by statistically 
significant lower values of total power of the spectrum and its VLF component compared to the control, with absence of significant differences in relation to other components (LF, HF). In group 4 (animals treated with PRX) we have demonstrated some statistically significant differences for all analysed parameters except for VLF, compared to the control. Animals in that group had the lowest value of LF and HF components (compared to the control and other groups) and the highest LF/HF ratio. Detailed numerical values are presented in Table II.

However, analysing percent distribution of individual spectral components in individual groups we have found no significant differences for the group 3 - animals treated with MLX - compared to the distribution of the control group (76.6 vs. 83.0 for \%VLF, 10.2 vs. 5.8 for $\% \mathrm{LF}$ and 13.2 vs. 11.2 for $\% \mathrm{HF}$, respectively), and for the group 2 - animals receiving PGF2 $\alpha$ prostaglandin analogue (78.4 vs. 83.0 for $\%$ VLF, 8.9 vs. 5.8 for $\%$ LF and 12.7 vs. 11.2 for $\% \mathrm{HF}$, respectively). On the other hand, HRV spectra for rats treated with PRX (group 4) were significantly different compared to the control, in terms of the percent share of VLF (significant increase: 94.1 vs. $83.0 ; \mathrm{p}=0.05$ ) and HF (significant decrease: 2.1 vs. $11.2 ; \mathrm{p}=$ 0.04) components, with no difference in terms of the percent share of the LF component (3.7 vs. 5.8). The results (expressed in $\log \%$ values) discussed above are presented in Figs 3-5.
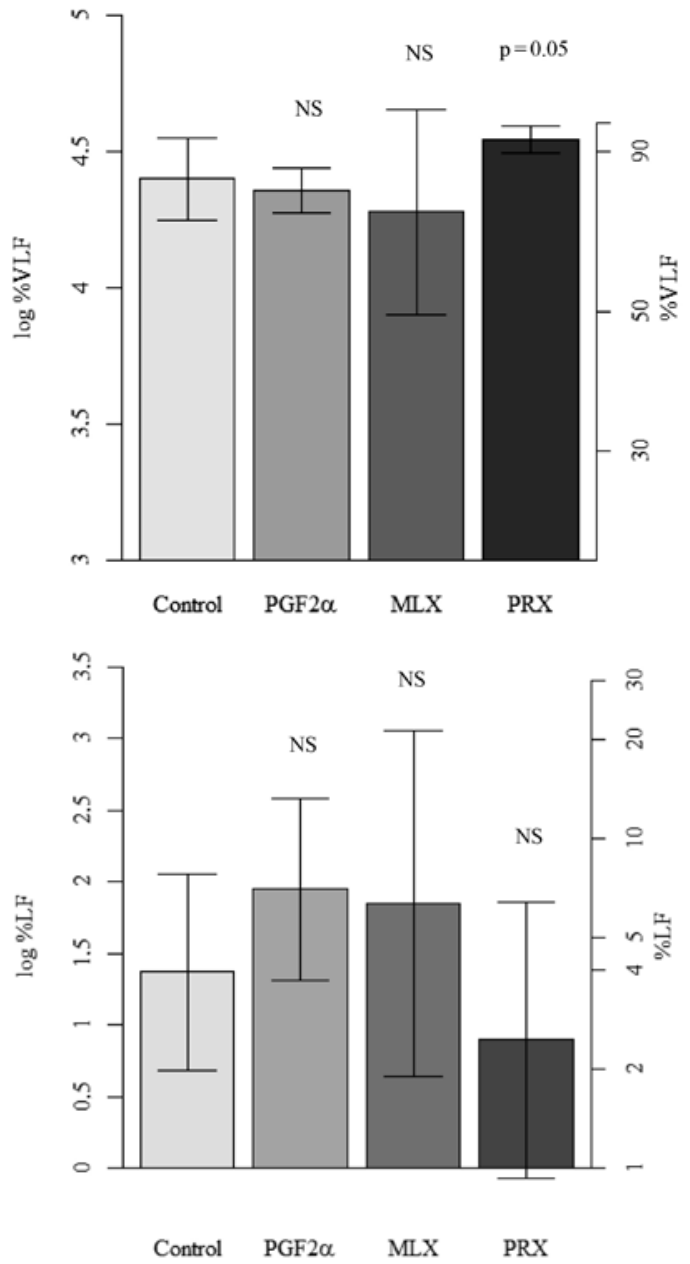

Fig. 3. The percentage participation of the very low frequency (VLF) component in the heart rate variability (HRV) spectrum

For all 3-7 figures: A box height stands for the mean value of a logarithm of a parameter in the particular group, and whiskers present the $95 \%$ confidence interval for the logarithm. Both scales: raw and logarithm, were marked to facilitate the interpretation.

A result of the statistical analysis was marked in relation to the control group ( $\mathrm{p}$ value or labelled as NS - non significant). MLX - meloxicam, PRX - piroxicam

Fig. 4. The percentage participation of the low frequency (LF) component

in the heart rate variability (HRV) spectrum 


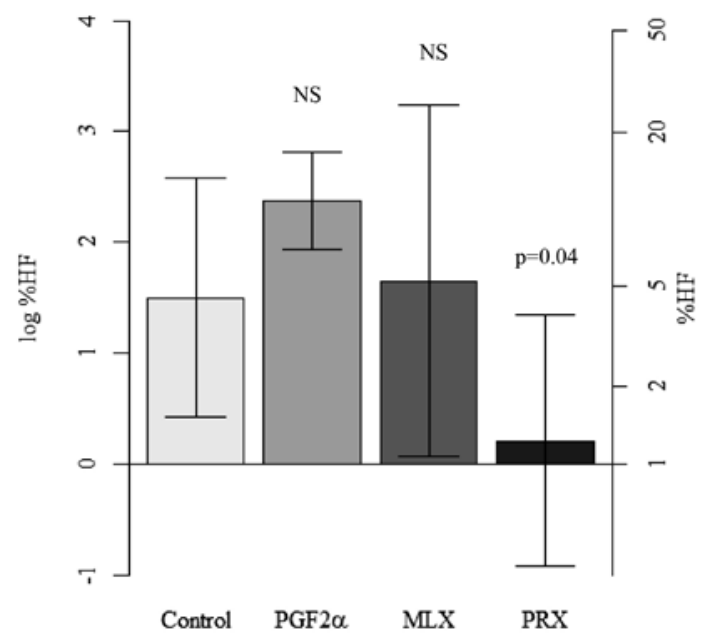

Fig. 5. The percentage participation of the high frequency (HF) component in the heart rate variability (HRV) spectrum

Assessing values of normalized HRV parameters we have demonstrated existence of statistically significant $(\mathrm{p}=0.03$ ) differences for the group of rats treated with PRX (group $4)$ : increase (nLF - 64.8) and decrease (nHF - 35.2), compared to the results obtained in the control group (49.1 and 50.9, respectively). In case of animals in other groups we have failed to demonstrate any significant differences either of $\mathrm{nLF}$ or of $\mathrm{nHF}$ compared to the control (group 2: nLF - 40.5, nHF - 59.6; group 3: nLF - 54.9, nHF - 45.1). The issues discussed above are illustrated (as log values) in Figures 6 and 7.

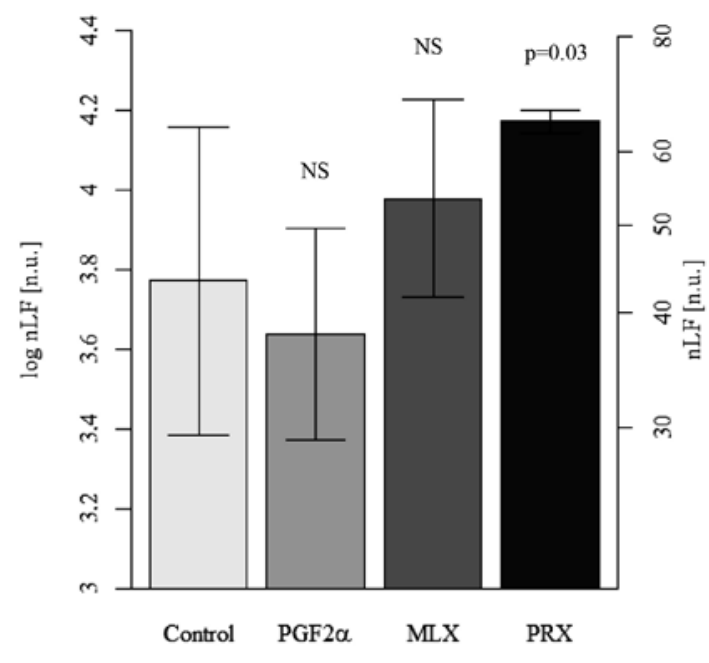

Fig. 6. Normalized LF (nLF) component in studied groups 


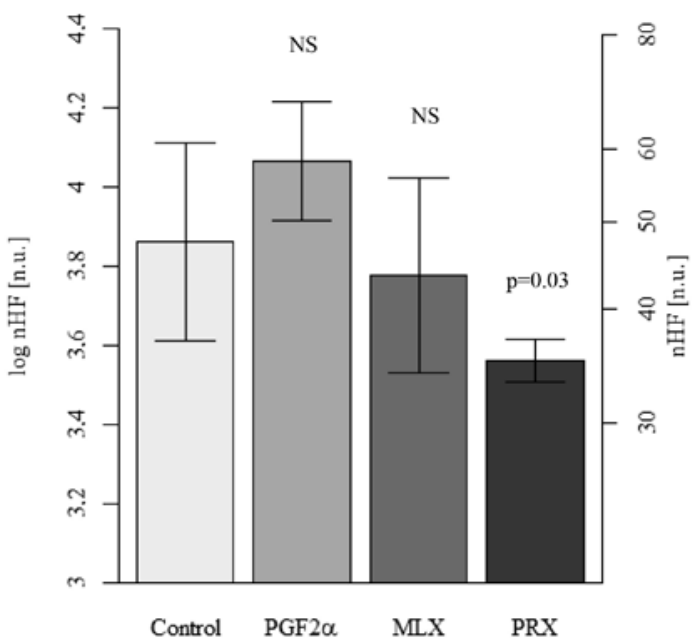

Fig. 7. Normalized HF (nHF) component in studied groups

Table II. Results of the spectral-domain HRV analysis

\begin{tabular}{|l|c|c|c|c|c|c|c|}
\hline & $\begin{array}{c}\text { PBOO Control } \\
\text { Group 1 }\end{array}$ & $\begin{array}{c}\text { PBOO+PGF2 } \alpha \\
\text { Group 2 }\end{array}$ & $\begin{array}{c}\text { PBOO+MLX } \\
\text { Group 3 }\end{array}$ & $\begin{array}{c}\text { PBOO+PRX } \\
\text { Group 4 }\end{array}$ & \multicolumn{3}{|c|}{ Statistic } \\
\cline { 5 - 8 } & & & & $\begin{array}{c}\text { Group } \\
\text { 1-2 }\end{array}$ & $\begin{array}{c}\text { Group } \\
\mathbf{1 - 3}\end{array}$ & $\begin{array}{c}\text { Group } \\
\mathbf{1 - 4}\end{array}$ \\
\hline $\begin{array}{l}\mathrm{TP} \\
{\left[\mathrm{ms}^{2}\right]}\end{array}$ & $43.34 \pm 35.64$ & $31.46 \pm 10.91$ & $17.20 \pm 11.30$ & $18.23 \pm 17.84$ & NS & 0.04 & 0.05 \\
\hline $\begin{array}{l}\mathrm{VLF} \\
{\left[\mathrm{ms}^{2}\right]}\end{array}$ & $33.38 \pm 27.94$ & $24.22 \pm 7.05$ & $14.41 \pm 12.66$ & $17.42 \pm 17.47$ & NS & 0.05 & NS \\
\hline $\begin{array}{l}\mathrm{LF} \\
{\left[\mathrm{ms}^{2}\right]}\end{array}$ & $2.99 \pm 3.39$ & $2.99 \pm 2.11$ & $1.28 \pm 0.92$ & $0.51 \pm 0.42$ & NS & NS & 0.03 \\
\hline $\begin{array}{l}\mathrm{HF} \\
{\left[\mathrm{ms}^{2}\right]}\end{array}$ & $6.97 \pm 12.33$ & $4.22 \pm 3.25$ & $1.52 \pm 1.69$ & $0.30 \pm 0.26$ & NS & NS & 0.05 \\
\hline $\mathrm{LF} / \mathrm{HF}$ & $1.25 \pm 0.75$ & $0.76 \pm 0.41$ & $1.36 \pm 0.61$ & $1.85 \pm 0.17$ & 0.05 & NS & 0.02 \\
\hline
\end{tabular}

\section{Discussion}

Considering the clinical interpretation of HRV component changes, results obtained in this experiment indicate existence of some significant changes in ANS function in PRX-treated animals with PBOO. According to the guidelines regarding HRV spectral analysis, the total power (TP) of the spectrum reflects the global ANS tension, the power of the HF component as well as the value of the normalized nHF parameter are positively correlated with parasympathetic activity, and the value of the standardised nLF parameter is directly proportional to the sympathetic activity. On the other hand, the power of the LF parameter depends on both sympathetic and parasympathetic activity $(26,29,39,40)$. Definition of the genesis and clinical importance of the VLF component is the most controversial issue. 
According to the majority of researchers the component is a reflection of the thermoregulative activity, RAA system and vascular tonus at rest maintenance (predominantly sympatheticallymediated) in the HRV spectrum $(26,29,39,40)$.

Thus, discussing results of our experiment in the perspective of accepted interpretation standards, it should be stated that a complete prostaglandin synthesis block with a nonselective cyclooxygenase inhibitor (piroxicam) caused reduction of the total autonomic tension (TP reduction) with a clearly marked decrease of the parasympathetic activity (decrease of $\mathrm{HF}, \mathrm{nHF}, \mathrm{HF} \%$ ). At the same time the functional parasympathetic withdrawal was associated with a relative sympathetic predominance (increase of nLF, VLF\%).

The therapy with meloxicam, associated with preferential COX-2 block, also resulted in reduction of total activity of the autonomic system, however without the marked functional disproportion of any of the two parts of the ANS. Thus, inhibition of synthesis of both constitutive (COX-1) and induced (COX-2) prostaglandins caused a reduction of the autonomic function, with decreased parasympathetic activity and a relative sympathetic predominance, and inhibition of COX-2-mediated prostaglandin synthesis resulted in absence of differential effect on activity of both parts of the ANS, although it was also manifested by reduction of the total ANS tension. Therefore, it should be expected that constitutive prostaglandins (synthesised by COX-1) account for the maintenance of the parasympathetic activity and, that way, to increased global ANS activity. However, the application of PGF2 $\alpha$ analogue (group 2) caused no significant increase of TP and parasympathetically-mediated HRV parameters (HF, nHF, partial LF) compared to the control group. However, if results obtained for the group 2 are compared to results for the groups 3 and 4 (which was formally not performed in the statistical analysis), a clear trend for normalisation of the discussed HRV parameters was observed, as expected. That was associated with the expected increase of both the total power spectrum and the power of its components LF and HF, percent share of those components and increased nHF value.

Moreover, in our opinion, a potentially different effect of various classes of prostaglandins in ANS activity modulation should be considered. The presence of prostacyclin (PGI2) as well as PGE2 and PGF2 was demonstrated in the human bladder. And conversely, in studies on rabbits a predominating character of PGE2 was demonstrated, as a main intravesically synthesised prostaglandin. However, considering results of numerous studies it should be stated that in physiological and pathophysiological conditions the bladder is a place of production and release of four basic classes of prostaglandins: PGE2, PGF2 $\alpha$, PGI2 and PGD2 (33). Therefore, our generalised reasoning regarding the role of prostaglandins in ANS activity modulation (particularly of the parasympathetic tension) is a cautious one, and largely based rather on conclusions from the HRV analysis with a complete blockade of synthesis of those compounds, than on direct results obtained for a group of animals treated with PGF2 $\alpha$ analogue (Enzaprost F5). We assume the existence of a difference in ANS modulation ability by various types of prostaglandins, although with a common general direction of changes, as suggested by HRV results obtained with a complete and non-selective block of all classes of those compounds.

HRV results and conclusions associated with the role of prostaglandin in neurogenic bladder control drawn by us are consistent with other reports $(18,27,36)$ indicating the role of those compounds in generation of bladder overactivity, mediated by activation of receptors EP1 and/or EP3 $(11,17,22)$.

Moreover, results of our experiment indicate that increased prostaglandin-dependent bladder contractile activity in the model of partial outflow obstruction may be also a result of 
autonomic activity modulation, with maintenance of the parasympathetic activity. According to the commonly accepted concept of the bladder physiology, its neurogenically controlled contractile activity results from stimulation of cholinergic receptors M1/M3 (1, 10). Therefore, the relative increase of parasympathetic activity may also account for symptoms of the bladder contractile overactivity in course of PBOO. At the same time, the fact may support the use of cyclooxygenase inhibitors (NSAID) in that illness (in the clinical sense - in BPH) as compounds that are able to correct the cholinergically-mediated bladder overactivity. As mentioned in the introduction, there are results of clinical trials indicating a potential effectiveness of NSAID in $\operatorname{BPH}(3,14,38)$. That effectiveness is also confirmed in some experimental studies - e.g. aspirin administered intravesically to rabbits with the experimental PBOO model caused a diminished contractile response to cholinergic stimulation (20).

Therefore, our results may support the hypothesis that the beneficial effect of NSAID on the bladder function in BPH may be not only a result of absence of EP1/EP3 receptors activation in conditions of blocked prostaglandin synthesis, but also of a reduced parasympathetic activity. On the other hand, our results are not clearly consistent with results obtained by Park et al. $(30,31)$, who demonstrated increased activity of the COX-2 isoform in PBOO conditions. Meloxicam-blocked COX-2 activity demonstrated in our experiment had a less pronounced effect on the ANS function compared to piroxicam. That allowed formulation of a hypothesis of a dominating role of constitutive prostaglandins (synthesised by COX-1), contrary to induced ones (synthesised with COX-2, and dominating according to Park et al. $(30,31)$ in PBOO) in modulation of the autonomic activity.

There is also a question of the effect of the study compounds on both bladder contractility and histological presentation of bladders in groups of animals, that is not completely consistent with expectations. A potential efficacy of NSAID on improved bladder function in PBOO was not reflected in either bladder compliance or the histological evaluation. Although in the bladder weight analysis we have demonstrated the lower BWW value in the group 4 $(\mathrm{PBOO}+\mathrm{PRX})$, suggesting indirectly a lower level of oedema, but in the group of animals treated with meloxicam - contrary to conclusions drawn by Park et al. $(30,31)$, BWW reached similar values as in the control group, despite blocking of the potentially dominating in PBOO COX-2 isoform. Moreover, the analysis of the BWW/final body weight ratio gave the opposite results, indicating a favourable effect of MLX, but not of PRX, on the bladder histology. Also, the histopathological description of bladders in each of the study groups, described above in Results section, indicated persistence of pathological histological changes despite administration of MLX or PRX. In our opinion, the above-mentioned discrepancies regarding the absence of expected favourable MLX/PRX effect on the bladder tissue are the result of a massive difference in final body weight of animals in groups 3 and 4, on one hand, and of short duration of the therapy, on the other. The urodynamic studies did not reveal any essential improvement in bladder functioning in any of the treated groups, although PRX administration seemed to slightly ameliorate bladder overactivity. The lack of the expected influence of the studied agents on the bladder motility may also result from the route of administration (we evaluated urodynamic parameters after the studied compounds were administered consistently i.p., not intravesically), as well as from the dosing regimen. Short treatment with the accepted dosage regimen was probably sufficient for generation of the ANS functional changes, but insufficient to cause some structural and physiological changes in bladder tissues. However, we tried to apply the doses of the studied agents in accordance with the literature reports. The choice of PGF $2 \alpha$ dose was based on reports published by 
Arend et al. (4), who used the dose of $250 \mu \mathrm{g} / \mathrm{kg}$ twice daily, which corresponded to approximately $125 \mu \mathrm{g} / \mathrm{rat}$. On the other hand, Hernandez et al. (16) used the dose of $400 \mu \mathrm{g} /$ rat, and found the dose to be a large, luteolytic PGF2 $\alpha$ dose. Therefore, we had decided to administer $200 \mu \mathrm{g}$ of PGF $2 \alpha$ prostaglandin analogue solution to animals in group 2 , according to the adopted dosage frequency. The selection of the meloxicam dose of $5 \mathrm{mg} / \mathrm{kg} \mathrm{b}$.w. was based on reports published by Laird et al. (21), who used the compound in rats at doses of $0.1-4 \mathrm{mg} / \mathrm{kg}$ b.w., every day for 5 days, and on the report published by Bourque et al. (7), who administered MLX at the dose of $1-2 \mathrm{mg} / \mathrm{kg}$ b.w. every day for 3 days, subcutaneously. Therefore, we had concluded that the meloxical administration regimen involving i.p. injections of $5 \mathrm{mg} / \mathrm{kg}$ b.w. of the drug every other day would finally be a similar dosage. In case of group 4 we have used the dose of $10 \mathrm{mg} / \mathrm{kg}$ b.w. piroxicam, considering experience of other researchers who used PRX at doses of $10 \mathrm{mg} / \mathrm{kg}$ b.w. (9) or $5 \mathrm{mg} /$ approx. $400 \mathrm{~g}$ rat (37).

We are aware of limitations of our reasoning regarding evaluation of the ANS activity based solely on the indirect HRV method. Moreover, as mentioned above, our reasoning regarding the effect of the studied PGF2 $\alpha$ analogue on the global ANS activity and the parasympathetic part was cautiously referred to the whole group of prostaglandins. We have studied PGF2 $\alpha$ alone (treating that class of compounds as representative bladder prostaglandins), but there are reports indicating species-related differences in synthesis of individual prostanoids. Maybe there are also various physiological aspects of the paracrine, intravesical activity of those compounds in relation to their effect on the ANS (although review of the literature confirms stimulatory effect of various prostaglandin classes on the bladder contractile activity). However, considering our overall results of HRV changes in PBOO rats obtained in conditions of a total, non-selective or partial COX blockade, and after administration of the PGF $2 \alpha$ analogue, in our opinion the hypothesis of modulating effect of COX-1 synthesised prostaglandins on the parasympathetic activity appears highly probable. Moreover, the hypothesis sanctions the validity of research on NSAID applicability in BPH. Our results indicate some additional, potentially important elements of pharmacodynamics of those drugs, allowing better understanding of their beneficial effect in pharmacotherapy of that illness.

\section{Acknowledgement}

This work was supported by the Jagiellonian University Medical College grant K/ZDS/004608.

\section{REFERENCES}

1. Andersson KE, Pehrson R: CNS involvement in overactive bladder. Drugs 63, 2595-2611 (2003)

2. Andersson KE: LUTS treatment: future treatment options. Neurourol. Urodyn. 26, 934-947 (2007)

3. Araki T, Yokoyama T, Kumon H: Effectiveness of a nonsteroidal anti-inflammatory drug for nocturia on patients with benign prostatic hyperplasia: a prospective non randomized study of loxoprofen sodium once daily before sleeping. Acta Med. Okayama 58, 45-49 (2004)

4. Arend A, Aunapuu M, Massob R, Selstam G: Prostaglandins of the E-series inhibit connective tissue proliferation in the liver wound of the rat. Ann. Anat. 187, 57-62 (2005)

5. Aubert AE, Ramaekers D, Beckers F, Breem R, Denef C, Van De Werf F, Ector H: The analysis of heart rate variability in unrestrained rats. Validation of method and results. Comput. Methods Programs Biomed. 60, 197-213 (1999)

6. Boon TA, Van Venrooij GE, Eckhardt MD: Effects of diabetes mellitus on lower urinary tract symptoms and dysfunction in patients benign prostatic hyperplasia. Curr. Urol. Rep. 2, 297-301 (2001) 
7. Bourque SL, Adams MA, Nakatsu K, Winterborn A: Comparison of buprenorphine and meloxicam for postsurgical analgesia in rats: effects on body weight, locomotor activity, and hemodynamic parameters. J. Am. Assoc. Lab. Anim. Sci. 49, 617-622 (2010)

8. Briganti A, Capitanio U, Suardi N, Gallina A, Salonia A, Bianchi M, Tutolo M, Di Girolamo V, Guazzoni G, Rigatti P, Montorsi F: Benign prostatic hyperplasia and its aetiologies. Eur. Urol. Suppl. 8, 865-871 (2009)

9. Buharalioglu CK, Korkmaz B, Cuez T, Sahan-Firat S, Sari AN, Malik KU, Tunctan B: Piroxicam reverses endotoxin-induced hypotension in rats: contribution of vasoactive eicosanoids and nitric oxide. Basic Clin. Pharmacol. Toxicol. 109, 186-194 (2011)

10. Clemens JQ: Basic bladder neurophysiology. Urol. Clin. North Am. 37, 487-494 (2010)

11. Coleman RA, Smith WL, Narumiya S: International Union of Pharmacology classification prostanoids receptors: properties, distribution and structure of the receptors and their subtypes. Pharmacol. Rev. 46, 205-229 (1994)

12. Dobrek $€$, Baranowska A, Thor PJ: Heart rate variability after BRL37344, a beta-3 agonist, in experimental bladder outlet obstruction. Postepy Hig. Med. Dosw. (Online) 67, 848-858 (2013)

13. Dobrek $€$, Thor PJ: The influence of melatonin and agomelatine on urodynamic parameters in experimental overactive bladder model - preliminary results. Postepy Hig. Med. Dosw. (Online) 65, 725-733 (2011)

14. Falahatkar S, Mokhtari G, Pourreza F, Asgari SA, Kamran AN: Celecoxib for treatment of nocturia caused by benign prostatic hyperplasia: a prospective, randomized, double-blind, placebo-controlled study. Urology 72, 813-816 (2008)

15. Goncalves H, Henriques-Coelho T, Bernardes J, Rocha AP, Brandao-Nogueira A, Leite-Moreira A: Analysis of heart rate variability in a rat model of induced pulmonary hypertension. Med. Eng. Phys. 32, 746-752 (2010)

16. Hernandez F, Peluffo MC, Stouffer RL, Irusta G, Tesone M: Role of the DLL4-NOTCH system in PGF2alphainduced luteolysis in the pregnant rat. Biol. Reprod. 84, 859-865 (2011)

17. Ikeda M, Kawatani M, Maruyama T, Ishihama H: Prostaglandin facilitates afferent nerve activity via EP1 receptors during urinary bladder inflammation in rats. Biomed. Res. 27, 49-54 (2006)

18. Ishizuka O, Mattiasson A, Andersson KE: Prostaglandin E2-iduced bladder hyperactivity in normal, conscious rats: involvement of tachykinins? J. Urol. 153, 2034-2038 (1995)

19. Kahokehr A, Vather R, Nixon A, Hill AG: Non-steroidal anti-inflammatory drugs for lower urinary tract symptoms in benign prostatic hyperplasia: systematic review and meta-analysis of randomized controlled trials. BJU Int. 111, 304-311 (2013)

20. Kibar Y, Irkilata HC, Yaman H, Onguru O, Coguplugil AE, Ergin G, Seyrek M, Yildiz O, Dayanc M: The effect of intravesical acetylsalicylic acid instillation on tissue prostaglandin levels after partial bladder outlet obstruction in rabbits. Neurourol. Urodyn. 30, 1646-1651 (2011)

21. Laird JMA, Herrero JF, De La Rubia GP, Cervero F: Analgesic activity of the novel COX-2 preferring NSAID, meloxicam in mono-arthritic rats: central and peripheral components. Inflamm. Res. 46, 203-210 (1997)

22. Lee T, Hedlund P, Newgreen D, Andersson KE: Urodynamic effects of a novel EP-1 antagonist in normal rats and rats with bladder outlet obstruction. J. Urol. 177, 1562-1567 (2007)

23. Lepor H: Medical treatment of benign prostatic hyperplasia. Rev. Urol. 13, 20-33 (2011)

24. Maggi CA, Meli A: Suitability of urethane anesthesia for physiopharmacological investigations in various systems. Part 1: general considerations. Experientia 42, 109-114 (1986)

25. Maggi CA, Meli A: Suitability of urethane anesthesia for physiopharmacological investigations in various systems. Part 2: cardiovascular system. Experientia 42, 292-297 (1986)

26. Malik M, Bigger JT, Camm AJ, Kleiger RE, Malliani A, Moss AJ, Schwartz PJ: Guidelines. Heart rate variability. Standards of measurements, physiological interpretations and clinical use. Task Force of the European Society of Cardiology and the North American Society of Pacing and Electrophysiology. Eur. Heart J. 17, 354-381 (1996)

27. McCafferty GP, Misajet BA, Laping NJ, Edwards RM, Thorneloe KS: Enhanced bladder capacity and reduced prostaglandin E2-mediated bladder hyperactivity in EP3 receptor knockout mice. Am. J. Physiol. Renal Physiol. 295, F507-F514 (2008)

28. Michel M, de la Rosette J: Medical treatment of lower urinary tract symptoms suggestive of benign prostatic hyperplasia. Eur. Urol. Suppl. 8, 496-503 (2009)

29. Omerbegovic M: Analysis of heart rate variability and clinical implications. Med. Arh. 63, 102-105 (2009)

30. Park JM, Yang T, Arend LJ, Schnermann JB, Peters CA, Freeman MR, Briggs JP: Obstruction stimulates COX2 expression in bladder smooth muscle cells via increased mechanical stretch. Am. J. Physiol. Renal Physiol. 276, F129-F136 (1999) 
31. Park JM, Yang T, Arend LJ, Smart AM, Schnermann JB, Briggs JP: Cyclooxygenase-2 is expressed in bladder during fetal development and stimulated by outlet obstruction. Am. J. Physiol. Renal Physiol. 273, F538-F544 (1997)

32. Parsons BA, Drake MJ (2011): Animal models in overactive bladder research. In: Handbook of Experimental Pharmacology, eds Andersson KE, Michel MC, Springer-Verlag Berlin, Heidelberg, pp. 15-43

33. Rahnama'i MS, van Kerrebroeck PE, de Wachter SG, van Koeveringe GA: The role of prostanoids in urinary bladder physiology. Nat. Rev. Urol. 9, 283-290 (2012)

34. Roehrborn CG: Benign prostatic hyperplasia: an overview. Rev. Urol. 7 suppl. 9, S3-S14 (2005)

35. Schroder A, Newgreen D, Andersson KE: Detrusor responses to prostaglandin E2 and bladder outlet obstruction in wild-type and Ep1 receptor knockout mice. J. Urol. 172, 1166-1170 (2004)

36. Schussler B: Comparision of the mode of action of prostaglandin E2 (PGE2) and sulprostone, a PGE2 derivative, on the lower urinary tract in healthy women. Urol. Res. 18, 349-352 (1990)

37. Shahzamani P, Takhtfooladi MA, Jahanshahi A, Sotoudeh A: Effects of dexamethasone, piroxicam and sterile aloe vera extract on the prevention of postoperative peritoneal adhesion formation in rat. Adv. Environ. Biol. 6 , 2851-2865 (2012)

38. St. Sauver JL, Jacobson DJ, McGree ME, Lieber MM, Jacobsen SJ: Protective association between nonsteroidal anti-inflammatory drug use and measures of benign prostatic hyperplasia. Am. J. Epidemiol. 164, 760-768 (2006)

39. Sztajzel J: Heart rate variability: a noninvasive electrocardiographic method to measure the autonomic nervous system. Swiss Med. Wkly. 134, 514-522 (2004)

40. Vanderlei LCM, Pastre CM, Hoshi RA, de Carvalho TD, de Godoy MF: Basic notions of heart rate variability and its clinical applicability. Rev. Bras. Cir. Cardiovasc. 24, 205-217 (2009)

41. Ventura S, Oliver VL, White CW, Xie JH, Haynes JM, Exintaris B: Novel drug targets for the pharmacotherapy of benign prostatic hyperplasia (BPH). Br. J. Pharmacol. 163, 891-907 (2011)

42. Zeng J, Pan C, Jiang C, Lindstrom S: Cause of residual urine in bladder outlet obstruction: an experimental study in the rat. J. Urol. 188, 1027-1032 (2012) 